Running Head: MENTAL DISORDER SYMPTOMS AMONG PARAMEDICS

\title{
Mental disorder symptoms among paramedics in a single Canadian site ${ }^{1}$
}

Justin Mausz, ACP, PhD(c), Peel Regional Paramedic Services, Operations, Fernforest Division, 1600 Bovaird Drive East, Brampton, Ontario, Canada, L6V 4R5 and McMaster University, Department of Health Research Methods, Evidence, and Impact, 1280 Main Street West, HSC-2C1, Hamilton, Ontario, Canada, L8S 4K1. (D) http://orcid.org/0000-0001-6955$\underline{5387}$

Elizabeth Anne Donnelly, NREMT, LICSW, PhD, the University of Windsor, School of Social Work, 167 Ferry Street, Room 167, Windsor, Ontario, Canada, N9A 0C5. http://orcid.org/0000-0001-9942-3203

Sandra Moll, OT, PhD, McMaster University, School of Rehabilitation Sciences, 1400 Main Street West, Institute for Applied Health Sciences (IAHS) Building, Room 403, Hamilton, Ontario, Canada, L8S 1C7. (D) http://orcid.org/0000-0002-1937-0103

Sheila Harms, MD, $\mathrm{PhD}(\mathrm{c})$, McMaster University, Department of Psychiatry and Behavioural Neurosciences, 100 West $5^{\text {th }}$ Street, Hamilton, Ontario, Canada, L8N 3K7. http://orcid.org/0000-0002-1752-2557

Meghan McConnell, PhD, the University of Ottawa, Department of Innovation in Medical Education, Faculty of Medicine, 850 Peter Morand Crescent, Room 102, Ottawa, Ontario, Canada, K1G 5Z3. (D) http://orcid.org/0000-0002-8721-2107

\footnotetext{
${ }^{1}$ Address correspondence to: Justin Mausz, Peel Regional Paramedic Services, Operations, Fernforest Division. 1600 Bovaird Drive East, Brampton, Ontario, Canada, L6V 4R5. Justin.Mausz@peelregion.ca
} 


\begin{abstract}
There is growing recognition in research and policy of a mental health crisis among Canada's paramedics but despite this, epidemiological surveillance of the problem is in its infancy. Just weeks before the emergence of the COVID-19 pandemic, we surveyed paramedics from a single, large, urban paramedic service in Ontario, Canada to assess for symptom clusters consistent with Post-Traumatic Stress Disorder (PTSD), major depressive disorder, and generalized anxiety disorder and to identify potential risk factors for each. In total, we received 589 completed surveys (a 97\% completion rate) and found that $11 \%$ screened positive for PTSD, $15 \%$ for depression, and 15\% for anxiety, with 1 in 4 active-duty paramedics screening positive for any of the three as recently as February 2020. In adjusted analyses, the risk of a positive screen varied as a function of employment classification, gender, self-reported resilience, and previous experience as a member of the service's peer support team. Our findings support the position that paramedics screen positive for mental disorders at high rates - a problem likely to have worsened since the onset of the COVID-19 pandemic. We echo the calls of researchers and policymakers for urgent action to support paramedic mental health in Canada.
\end{abstract}

\title{
Key Words
}

Public Safety Personnel; First Responders; Mental Disorders; Mental Health; Well-Being; Trauma; Operational Stress Injuries; Post-Traumatic Stress Injuries; Resilience; Peer Support 


\section{Introduction}

A 2012 systematic review and meta-analysis calculated the international pooled prevalence of Post-Traumatic Stress Disorder (PTSD) among 'rescue workers' at 10\% [1]. When stratified by occupation, 'ambulance workers' were found to have a pooled prevalence of PTSD of 14\% [1]. In fact, the 'ambulance worker' strata was used as the reference category in the authors' relative risk modelling, with Berger et al. suggesting that 'ambulance personnel' may be "more susceptible to PTSD” (p. 1009) [1]. The findings parallel a growing body of research internationally that points to high rates of mental disorders among Emergency Medical Services (EMS) workers [2-8] both in general and comparatively within first responder occupations. Addressing a conspicuous absence of similar research in Canada, a recent national survey of Public Safety Personnel (PSP) found that 1 in 4 participating paramedics screened positive for PTSD, 1 in 3 for major depressive disorder, and 1 in 3 for an anxiety disorder, with nearly half screening positive for any one mental disorder [9] and more frequent positive screens observed among women paramedics. Related research has also suggested that exposure to potentially psychologically traumatic events [10-16]; symptoms consistent with chronic pain, [17] clinical insomnia [18] and alcohol use disorder [9]; suicidal ideation, planning, and attempts [19]; and a history of adverse childhood experiences [20] are prevalent among paramedics, again varying across demographic categories, including gender. The downstream consequences are potentially significant, and can include lost time from work [21], family hardship [22], reduced quality of life [23-26], and suicidality [7,27], all of which can contribute to burnout [6,28], workplace incivility [29,30], attrition [31] and potentially compromise patient care [32]. As a result, the situation has been characterized in research and policy as a 'crisis in Canada' [33,34]. 
One response to the problem has been a growing interest in workplace resiliency training programs. Resilience is generally held to be the ability for individuals to 'bounce back' from adversity [35], and the resilience narrative suggests that: (1) individuals can cultivate skills that enhance their resilience; and (2) 'more resilient' individuals may be less susceptible to mental health challenges, owing to proactive psychological protection [36-40]. The result has been an increasing adoption of workplace resiliency training within the public safety professions through programs such as the Road to Mental Readiness (R2MR) developed by the Canadian Armed Forces [41], its civilian analogue The Working Mind [42] and a new, PSP-specific program called Before Operational Stress [40]. Evidence supporting the resilience hypothesis, however, has generally been underwhelming, with recent research showing only small effects on mental health literacy, stigma reduction, or mental disorder symptoms [43-45].

Any response to the mental health crisis within the paramedic community requires a nuanced understanding of the epidemiology mental disorders among paramedics. Although the extant research in Canada paints a concerning picture, there are methodological limitations that cloud its interpretation. In generating the dataset, the research team cast an intentionally broad net, using a combination of social media advertising, and employer and paramedic association list servers to recruit participants. In total, approximately 600 paramedics from across Canada participated, but both the response rate and characteristics of the population from which the sample was drawn are unknown. This makes understanding the scope of the problem challenging, as results from self-selected samples can be difficult to interpret. It may be, for example, that paramedics with (current or former) mental health challenges are more likely to 
volunteer for survey research on the topic. Or, conversely, the opposite may be true. In either case, however, the precision of the existing prevalence estimates - and by extension, our understanding of risk factors - may be called into question when the representativeness of study samples is uncertain. Therefore, our objective was to estimate the proportion of symptom clusters consistent with various mental disorders among paramedics in a single, large, urban paramedic service in Ontario, Canada. Given the growing interest in the resilience narrative in the population, we also sought to explore the relationship between self-reported resilience on the risk of a positive screen for a mental disorder. Our study draws on and (to a degree) replicates the work of Carleton and colleagues [9] on a smaller scale while carefully controlling participant selection within a single site.

\section{Methods}

\section{Overview}

Our study took place pre-COVID-19 between September 2019 through February 2020. We distributed an in-person cross-sectional survey to a single, large, urban paramedic service in Ontario, Canada. In addition to a demographic questionnaire, our survey contained validated self-report symptom measures for PTSD, generalized anxiety disorder, and major depressive disorder, as well as a self-report measure for resilience. Our study received ethics approval from the Hamilton Integrated Research Ethics Board (HiREB protocol number 7595), and all respondents provided informed consent to participate. Italicized terms are in reference to the definitions provided by the Canadian Institute for Public Safety Research and Treatment in their Glossary of Terms (version 2.1) [46]. 


\section{Setting and Participants}

We conducted our study in Peel Region, Ontario, Canada. Peel Regional Paramedic Services is the publicly funded sole provider of land ambulance and paramedic services to the municipalities of Brampton, Mississauga, and Caledon, with a total population of 1.3 million residents across a mixed suburban and rural geography of $1,200 \mathrm{~km}^{2}$. At the time of recruitment, the service employed a total of 714 paramedics responding to approximately 130,000 emergency calls annually, making the service the second largest in the province by staffing and caseload. Workplace resiliency training in the form of the R2MR program [41] was launched in the service in 2017 .

Paramedics in Peel Region are required to complete semi-annual continuing medical education (CME) days. We distributed our survey during the fall 2019 / winter 2020 CME sessions. Following a brief presentation by the principal investigator, consenting paramedics were given approximately 20 minutes at the beginning of the day to complete the survey. All participants were given a list of mental health resources available in the community and a \$10 Tim Horton's gift card. This recruitment strategy has been used previously among paramedic services in Ontario [47] and was specifically chosen for its potential to generate high response rates.

\section{Survey}

Unlike in previous studies, in which participants could complete surveys over multiple sittings, our participants had only a limited amount of time during their CME to participate. This 
necessarily constrained the number, length, and complexity of questionnaires we could include in our survey. Each instrument is described below.

\section{Demographics}

Our demographic questionnaire was developed through consensus among the research team and was intended to gather data on criteria identified in the literature to be associated with mental disorder symptoms among paramedics. This included age, gender, relationship status, education, provider classification (primary or advanced care), employment classification (full vs. part-time), years of experience, and current or previous participation on the service's peer support team. The peer support team was established in 2017 and was originally intended to provide non-clinical, empathetic support for home and family stressors.

We decided not to collect data on race or ethnicity. While the link between race and ethnicity and health is well-established [48,49], and other studies of symptom clusters consistent with mental disorders among paramedics have included ethnicity as a potential predictor [9], the relative racial and ethnic homogeneity of our sample (an extrapolation based on similar research [9,50-52]) would likely have left our study under-powered to detect such an effect.

\section{Resilience}

We evaluated self-reported resilience using the 5-item Brief Resilience Scale (BRS) [53]. The BRS asks respondents to rate their agreement with various statements that characterize how well they recover from adversity (i.e., "I tend to bounce back quickly after hard times"). Response options range from 1 ("Strongly Disagree") to 5 ("Strongly Agree"). After reverse coding three 
items, the scores are summed and divided by the number of items answered. The scale categorizes respondents into 'low' $(<3)$, 'normal' (3.00-4.30) or 'high' (>4.31) levels of resilience [53] and has been used in at least one previous study among Public Safety Personnel in Canada [45]. Based on the resilience narrative, we hypothesized that self-reported resilience scores would be inversely associated with the risk of a positive screen for a mental disorder.

\section{Self-Report Symptom Measures}

The PTSD Checklist-5 (PCL-5; [54]) is a 20-item self-report measure that assesses four criteria specified in the Diagnostic and Statistical Manual (DSM) version 5 for diagnosing PTSD: intrusion, avoidance, alterations in cognition or mood, and arousal or reactivity. Symptoms are rated on a 5-point anchored scale from 0 ("Not at all") to 5 ("Extremely") within the past 30 days. Possible scores range from 0 to 80 , with a summed score $>31-33$ providing a sensitivity of $88 \%$ and a specificity of $69 \%$ for probable PTSD [55] when compared to clinical interviews. Consistent with similar studies in this population[9], we used a cut score of $>32$ to indicate a positive screen for PTSD. Typically, the diagnosis of (or screening for) PTSD is made in reference to an index trauma ('Criterion A'), evaluated using a separate questionnaire. However, given the increasing recognition in scholarship and policy that public safety personnel encounter multiple potentially psychologically traumatic events during their work [10,13], we omitted the Criterion A screen.

To evaluate for symptoms of major depressive disorder, we used the 9-item Patient Health Questionnaire (PHQ-9) [56]. The PHQ-9 assesses the degree to which depressive symptoms (such as loss of interest, or difficulty concentrating) have affected the respondent over the past 14 
days. Symptoms are rated on a 4-point anchored scale from 0 ("Not at All") to 3 ("Nearly Every Day"), with summed scores $>9$ corresponding to an $85 \%$ sensitivity and $82 \%$ specificity for probable depression when compared to clinical interviews [57].

Finally, to evaluate for symptoms of generalized anxiety disorder, we used the 7-item Generalized Anxiety Disorder (GAD-7) scale [58]. The GAD-7 assesses the degree to which symptoms of anxiety (such as feeling on edge) have affected the respondent over the last 14 days on a 4-point anchored scale from 0 ("Not at All”) to 3 ("Nearly Every Day") with summed scores $>9$ corresponding to an $89 \%$ sensitivity and an $82 \%$ specificity for probable generalized anxiety disorder when compared to clinical interviews [58].

\section{Analysis}

We used descriptive statistics to characterize our data, including measures of central tendency, distribution (e.g., skewness and kurtosis), and dispersion for continuous variables and counts and percentages for categorical data. To explore group differences among our participants, we used one-way analysis of variance (ANOVA) and chi-square tests for continuous and categorical data, respectively. To evaluate the internal consistency of the self-report measures, we calculated Cronbach's alpha for each screening tool.

We used logistic regression modelling to explore the relationship between demographic characteristics and self-reported resilience on the risk of positive mental disorder screens. We first constructed unadjusted, univariate logistic regression models to test the association between each demographic variable and our outcomes of interest. Given the exploratory nature of our 
study, we then entered all demographic variables into adjusted logistic regression models, making no effort to organize the variables hierarchically based on theoretical or statistical significance. Where we made an effort at organizing our model parameters was in the exploration of interaction effects. Here, we constructed interaction terms based on group differences in demographic variables and their association with our outcomes of interest in our unadjusted models. Importantly, our primary interest was in the individual odds ratios of the covariates we included, rather than the predictive capacity of the models as a whole

\section{Results}

\section{Participation \& Response Rate}

We distributed a total of 607 surveys to paramedics attending the fall 2019 CME sessions, of which 600 completed surveys were returned. Of these, we excluded 11 for large portions of incomplete data, leaving a final sample of 589 surveys for analysis, corresponding to a response rate of $98.8 \%$ and a completion rate of $97 \%$.

During the CME sessions, a total of 107 paramedics (15\% of the total workforce) were on longterm leave (Figure 1). Although we originally intended to distribute surveys to paramedics on leave via postal mail early in the new year, personnel within the service who could have facilitated this stage of recruitment were redeployed in response to the COVID-19 pandemic and we were unable to contact paramedics on leave. 


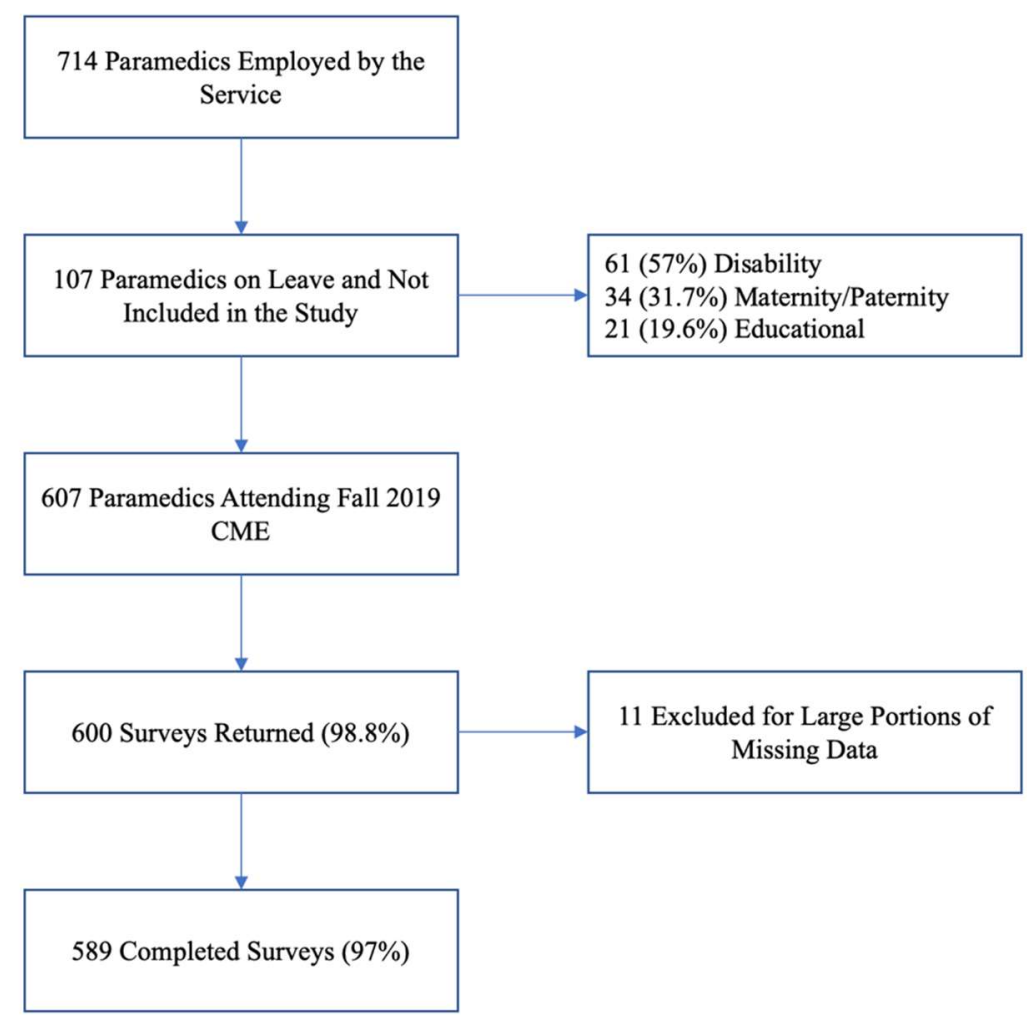

Figure 1: Participant flow diagram

\section{Participant Characteristics}

In total, 354 of our participants (60.1\%) were men, $232(39.3 \%)$ women, and a small number (not reported to preserve anonymity) provided another, non-binary gender. The participants were on average $34.58( \pm 8.21)$ years of age and reported an average of $9.30( \pm 0.44)$ years of experience as paramedics. The majority (59.1\%) of our participants were married or living common-law (later collapsed into single $(143 ; 24.3 \%)$ or relationship $(446 ; 75.7 \%)$ ), had completed a college diploma as their highest education (49.2\%), were working full-time (66.8\%), in a front-line role (93.8\%), and practicing at the primary care paramedic certification $(67.7 \%)$. Five percent $(n=29)$ of our participants reported being a current or former member of the service's peer support team. 
When stratified by gender, women were on average younger (33.61 vs. 35.13 years of age, $F=$ 5.35; $p=0.02)$, had less experience ( 8.45 vs. 9.79 years, $F=5.2 ; p=0.02)$, and were more likely to have completed an undergraduate university degree (Odds Ratio [OR] 2.02, 95\% Confidence Interval $[\mathrm{CI}] 1.44-2.83 ; p<0.001)$, but less likely to practice at the advanced care paramedic certification (OR 0.61, 95\% CI 0.42-0.88; $p=0.009$ ). Our point estimates suggested women were also less likely to work full-time (OR $0.77,95 \%$ CI $0.54-1.09$ ) and more likely to be (or to have been) members of the peer support team (OR 1.25, 95\% CI 0.59-2.65); however, neither difference reached the 5\% significance threshold ( $p=0.14$ and 0.55 , respectively).

\section{Resilience}

The internal consistency for the BRS in our survey was 0.85 , consistent with previous investigations [45]. Across all participants, the average BRS score was 3.73 (95\% Confidence Interval [CI] 3.68-3.79), corresponding to "Normal" levels of resilience [53]. A total of 63 $(10.6 \%)$ of our participants met the criteria for "Low" levels of resilience. While mean BRS scores were higher among participants in a relationship (3.77 (SD 0.68) vs. 3.62 (SD 0.61), $p=0.002)$ and advanced (compared to primary) paramedics (3.82 (SD 0.65) vs. 3.69 (SD 0.67), $p=0.02$ ), we did not observe any significant differences in the proportions of participants meeting the threshold for "Low" resilience across demographic categories.

\section{Mental Disorder Symptom Clusters}

Internal consistency measures for the PCL-5 $(\boldsymbol{\alpha}=0.94)$, PHQ-9 $(\boldsymbol{\alpha}=0.87)$, and GAD-7 $(\boldsymbol{\alpha}=$ 0.92) were all high and consistent with other investigations [55,59-61]. Mean reporting scores 
stratified by demographic characteristics are presented in Table 1. In total, 66 participants $(11.2 \%)$ met the criteria for a positive screen for PTSD, 91 (15.4\%) for major depressive disorder, and 87 (14.7\%) for generalized anxiety disorder, with 145 participants $(24.6 \%)$ screening positive for any of the three.

\begin{tabular}{|c|c|c|c|c|c|c|}
\hline \multicolumn{2}{|c|}{ Demographic Category } & $\mathbf{N}(\%)$ & $\begin{array}{c}\text { BRS } \\
\text { Range 1-5 } \\
\text { Mean (SD) }\end{array}$ & $\begin{array}{c}\text { PCL-5 } \\
\text { Range 0-80 } \\
\text { Mean (SD) }\end{array}$ & $\begin{array}{c}\text { PHQ-9 } \\
\text { Range 0-27 } \\
\text { Mean (SD) }\end{array}$ & $\begin{array}{c}\text { GAD-7 } \\
\text { Range 0-21 } \\
\text { Mean (SD) }\end{array}$ \\
\hline All Participants & & 589 & $3.73(0.67)$ & $13.98(4.16)$ & $4.73(4.74)$ & $4.46(4.76)$ \\
\hline \multirow[t]{2}{*}{ Gender } & Men & $354(60 \%)$ & $3.77(0.65)$ & $13.69(0.72)$ & $4.34(4.28)$ & $3.87(4.23)$ \\
\hline & Women & $232(39 \%)$ & $3.67(0.69)$ & $14.50(0.99)$ & $5.34(5.34)^{*}$ & $5.38(5.38)^{* * *}$ \\
\hline \multirow{2}{*}{$\begin{array}{l}\text { Relationship } \\
\text { Status }\end{array}$} & Single & $143(24 \%)$ & $3.62(0.61)$ & $14.17(14.28)$ & $5.25(4.79)$ & $4.71(4.75)$ \\
\hline & Relationship & $446(76 \%)$ & $3.77(0.68)^{*}$ & $13.92(14.14)$ & $4.57(4.72)$ & $4.37(4.70)$ \\
\hline \multirow[t]{2}{*}{ Employment } & Part-Time & $194(33 \%)$ & $3.74(0.66)$ & $10.85(11.90)$ & $3.70(4.32)$ & $3.29(4.08)$ \\
\hline & Full-Time & $39467 \%)$ & $3.73(0.67)$ & $15.56(14.92)^{* * *}$ & $5.24(4.86)^{* * *}$ & $5.04(4.97)^{* * *}$ \\
\hline \multirow[t]{2}{*}{ Education } & College & $330(56 \%)$ & $3.71(0.67)$ & $14.77(14.33)$ & $4.97(4.97)$ & $4.75(4.84)$ \\
\hline & University & $259(44 \%)$ & $3.76(0.65)$ & $12.98(13.91)$ & $4.42(4.60)$ & $4.09(4.64)$ \\
\hline \multirow{2}{*}{$\begin{array}{l}\text { Provider } \\
\text { Classification }\end{array}$} & PCP & $398(67 \%)$ & $3.69(0.67)$ & $13.30(13.62)$ & $4.77(4.82)$ & $4.45(4.82)$ \\
\hline & $\mathrm{ACP}$ & $188(32 \%)$ & $3.82(0.65)^{*}$ & $15.42(15.16)$ & $4.64(4.57)$ & $4.48(4.64)$ \\
\hline \multirow{2}{*}{$\begin{array}{l}\text { Peer Support } \\
\text { Team }\end{array}$} & Member & $29(45 \%)$ & $3.54(0.82)$ & $23.41(22.59)^{* * *}$ & $7.76(6.42)^{* * *}$ & $7.38(6.50)^{* *}$ \\
\hline & Non-Member & $560(95 \%)$ & $3.74(0.66)$ & $13.53(13.46)$ & $4.58(4.60)$ & $4.31(4.62)$ \\
\hline
\end{tabular}

Table 1: Mental disorder symptom scores (mean score) stratified by demographic category. SD $=$ Standard Deviation; BRS = Brief Resilience Scale; PCL-5 = Post-Traumatic Stress Disorder Checklist; PHQ-9 = Patient Health Questionnaire; GAD-7 = Generalized Anxiety Disorder. ${ }^{*} p<0.05^{* *} p<0.01{ }^{* * *} p<0.001$

\section{Unadjusted Models}

In our unadjusted models (Table 2a), age (OR 1.04, 95\% CI 1.01-1.06 $p<0.001$ ), experience (OR $1.05,95 \%$ CI 1.02-10.7, $p<0.001$ ), working full-time (OR 2.72, 95\% CI 1.77-4.50, $p=0.003$ ), 
being (or having been) a member of the peer support team (OR 3.03, 95\% CI 1.42-6.45, $p=$ 0.004), and "low" resilience (OR 8.15, 95\% CI 4.62-14.36, $p<0.001)$ were all associated with an increased risk of screening positive for any one of PTSD, major depressive disorder, or generalized anxiety disorder.

The risk of a positive screen additionally varied across demographic categories, depending on the outcome being tested, the results of which are presented in Table $2 \mathrm{a}$. 


\begin{tabular}{|c|c|c|c|c|c|c|c|c|c|c|}
\hline \multirow{3}{*}{$\frac{\text { All Participants }[\mathrm{N}(\%)]}{\text { Covariate }}$} & \multirow{2}{*}{\multicolumn{2}{|c|}{$\begin{array}{l}\text { BRS }<3.00 \\
63(10.7 \%)\end{array}$}} & \multirow{2}{*}{\multicolumn{2}{|c|}{$\begin{array}{l}\text { PCL-5 >32 } \\
66(11.2 \%)\end{array}$}} & \multirow{2}{*}{\multicolumn{2}{|c|}{$\begin{array}{l}\text { PHQ-9 >9 } \\
91(15.4 \%)\end{array}$}} & \multirow{2}{*}{\multicolumn{2}{|c|}{$\begin{array}{l}\text { GAD-7 }>9 \\
87(14.7 \%)\end{array}$}} & \multirow{2}{*}{\multicolumn{2}{|c|}{$\begin{array}{c}\text { Any } \\
145(24.6 \%)\end{array}$}} \\
\hline & & & & & & & & & & \\
\hline & OR & $95 \%$ CI & OR & $95 \%$ CI & OR & $95 \%$ CI & OR & $95 \%$ CI & OR & $95 \%$ CI \\
\hline Age & 0.99 & $0.96-1.02$ & $1.06^{* * *}$ & $1.02-1.09$ & $1.04^{* * *}$ & $1.02-1.07$ & $1.03^{*}$ & $1.00-1.06$ & $1.04^{* * *}$ & $1.01-1.06$ \\
\hline Experience & 0.99 & $0.95-1.02$ & $1.05^{* * *}$ & $1.02-1.09$ & $1.04^{* *}$ & $1.01-1.07$ & $1.03^{* *}$ & $1.00-1.06$ & $1.04^{* * *}$ & $1.02-1.07$ \\
\hline Women & 1.35 & $0.79-2.27$ & 0.73 & $0.43-1.26$ & $1.61^{*}$ & $1.02-2.52$ & $1.88^{* *}$ & $1.19-2.98$ & 1.38 & $0.94-2.02$ \\
\hline Single & 1.38 & $0.78-2.46$ & 0.81 & $0.43-1.52$ & 1.21 & $0.73-2.00$ & 1.13 & $0.67-1.90$ & 1.25 & $0.81-1.91$ \\
\hline Full-Time & 0.78 & $0.45-1.34$ & $2.72^{* *}$ & $1.39-5.33$ & $2.87^{* * *}$ & $1.60-5.16$ & $2.63^{* * *}$ & $1.50-4.83$ & $2.82^{* * *}$ & $1.77-4.50$ \\
\hline College & 0.97 & $0.57-1.64$ & 1.53 & $0.89-2.61$ & 1.32 & $0.78-1.94$ & $1.78^{*}$ & $1.10-2.89$ & 1.43 & $0.97-2.11$ \\
\hline $\mathrm{ACP}$ & 0.76 & $0.42-1.36$ & 1.54 & $0.91-2.60$ & 0.98 & $0.61-1.59$ & 1.00 & $0.61-1.63$ & 1.06 & $0.71-1.58$ \\
\hline Peer Supporter & 1.35 & $0.45-4.01$ & $4.70^{* * * *}$ & $2.08-10.62$ & $4.72^{* * *}$ & $1.96-9.28$ & $2.76^{*}$ & $1.21-6.28$ & $3.02^{* *}$ & $1.42-6.45$ \\
\hline Low Resilience $(\mathrm{BRS}<3.00)$ & & & $9.30^{* * *}$ & $5.12-16.89$ & $6.34^{* * *}$ & $3.61-11.12$ & $6.29^{* * *}$ & $3.57-11.08$ & $8.15^{* * *}$ & $4.62-14.36$ \\
\hline
\end{tabular}

Table 2a: Positive mental disorder screens stratified by demographics and resilience in unadjusted analyses. $\mathrm{SD}=\mathrm{Standard} \mathrm{Deviation}$; OR $=\mathrm{Odds}$ Ratio; $\mathrm{PCP}=$ Primary Care Paramedic; ACP = Advanced Care Paramedic; BRS = Brief Resilience Scale; PCL = Post-Traumatic Stress Disorder Checklist; GAD = Generalized Anxiety Disorder. "Any" = any positive screen excluding BRS. ${ }^{*} p<0.05{ }^{* *} p<0.01{ }^{* * *} p<0.001$ 


\section{Adjusted Models}

Given the exploratory nature of our study, we included all demographic variables in our adjusted models. We also included interaction terms for gender*education (college versus university) and gender*employment status (part-time versus full-time) given the group differences we observed.

In our adjusted models, working full-time (OR 3.06, 95\% CI 1.70-5.50, $p<0.001)$ and having "low" resilience (OR 10.41, 95\% CI 5.59-19.40, $p<0.001)$ were the only characteristics associated with an increased risk of our composite outcome of a positive screen for any one of PTSD, major depressive disorder, or generalized anxiety disorder.

While "low" resilience persisted as a significant association when evaluating mental disorder symptom clusters, the associations with other demographic characteristics varied depending on the outcome being tested (Table $2 b)$. 


\begin{tabular}{|c|c|c|c|c|c|c|c|c|}
\hline \multirow{3}{*}{$\frac{\text { Model }\left[\left(\mathrm{x}^{2}(p)\right]\right.}{\text { Covariate }}$} & \multirow{2}{*}{\multicolumn{2}{|c|}{$\begin{array}{c}\text { PCL-5 }>\mathbf{3 2} \\
82.19(p<0.001)\end{array}$}} & \multirow{2}{*}{\multicolumn{2}{|c|}{$\begin{array}{c}\text { PHQ-9 }>9 \\
78.30(p<0.001)\end{array}$}} & \multirow{2}{*}{\multicolumn{2}{|c|}{$\begin{array}{c}\text { GAD-7 }>\mathbf{9} \\
72.14(p<0.001)\end{array}$}} & \multirow{2}{*}{\multicolumn{2}{|c|}{$\begin{array}{c}\text { Any Positive Screen } \\
101.3(p<0.001)\end{array}$}} \\
\hline & & & & & & & & \\
\hline & OR & $95 \%$ CI & OR & $95 \%$ CI & OR & $95 \%$ CI & OR & $95 \%$ CI \\
\hline Age & $1.07^{*}$ & $1.00-1.13$ & $1.06^{*}$ & $1.00-1.11$ & 1.02 & $0.96-1.08$ & 1.02 & $0.97-1.07$ \\
\hline Experience & 0.96 & $0.90-1.03$ & 0.97 & $0.91-1.03$ & 0.99 & $0.93-1.05$ & 1.00 & $0.95-1.06$ \\
\hline Women & 0.73 & $0.39-1.37$ & $1.78^{*}$ & $1.07-2.95$ & $2.20^{* *}$ & $1.32-3.67$ & 1.52 & $0.98-2.34$ \\
\hline Single & 0.95 & $0.46-1.96$ & 1.35 & $0.76-2.40$ & 1.22 & $0.68-2.19$ & 1.45 & $0.88-2.34$ \\
\hline Full-Time & 2.15 & $0.93-4.96$ & $2.85^{* *}$ & $1.41-5.77$ & $2.85^{* *}$ & $1.41-5.77$ & $3.06^{* * *}$ & $1.70-5.50$ \\
\hline University & 0.70 & $0.37-1.32$ & 0.82 & $0.48-1.39$ & $0.50^{*}$ & $0.29-0.86$ & 0.70 & $0.45-1.10$ \\
\hline Advanced Care & 1.19 & $0.62-2.28$ & 0.77 & $0.40-1.29$ & 0.82 & $0.45-1.46$ & 0.76 & $0.46-1.24$ \\
\hline Peer Supporter & $4.05^{* *}$ & $1.57-10.43$ & $3.31^{* *}$ & $1.40-7.84$ & 2.07 & $0.83-5.14$ & 2.13 & $0.92-4.89$ \\
\hline 'Low’ Resilience $(\mathrm{BRS}<3.00)$ & $13.09^{* * *}$ & $6.70-25.54$ & $7.65^{* * *}$ & $4.14-14.10$ & $7.33^{* * *}$ & $3.96-13.55$ & $10.41^{* * *}$ & $5.59-19.40$ \\
\hline Model $\left[\mathrm{x}^{2}(p)\right]$ & \multicolumn{2}{|c|}{$0.41(p=0.81)$} & \multicolumn{2}{|c|}{$0.911(p=0.63)$} & \multicolumn{2}{|c|}{$0.75(p=0.68)$} & \multicolumn{2}{|c|}{$1.06(p=0.58)$} \\
\hline Interaction Term & OR & $95 \%$ CI & OR & $95 \%$ CI & OR & $95 \%$ CI & OR & $95 \%$ CI \\
\hline Gender*University & 1.48 & $0.42-5.32$ & 0.62 & $0.22-1.75$ & 0.97 & $0.33-2.85$ & 0.68 & $0.28-1.66$ \\
\hline Full-Time*Gender & 0.90 & $0.19-4.19$ & 0.77 & $0.22-2.72$ & 0.56 & $0.15-2.07$ & 0.70 & $0.24-1.97$ \\
\hline
\end{tabular}

Table 2b: Positive mental disorder screens stratified by demographics and resilience in adjusted analyses. $\mathrm{SD}=\mathrm{Standard}$ Deviation; $\mathrm{OR}=\mathrm{Odds}$ Ratio; $\mathrm{PCP}=$ Primary Care Paramedic; ACP = Advanced Care Paramedic; BRS = Brief Resilience Scale; PCL = Post-Traumatic Stress Disorder Checklist; GAD = Generalized Anxiety Disorder; "Any" = any positive screen ${ }^{*} p<0.05^{* *} p<0.01{ }^{* * *} p<0.001$ 


\section{Discussion}

The goals of this study were to estimate the proportions of symptom clusters consistent with three specific mental disorders potentially associated with public safety work, and to explore the relationship between mental disorder symptoms and demographic variables and self-reported resilience. Because much of the extant research has relied social media or email list servers to recruit participants, the concern is that the possibility of response bias may produce results that over or underestimate the true prevalence. In that respect, our response rate of $98 \%$ is a strength of our investigation, but our results findings are simultaneously encouraging and concerning.

Among our sample, 11\% of our participants screened positive for PTSD, 15\% for major depressive disorder, and $15 \%$ for generalized anxiety disorder, with $25 \%$ screening positive for any one of the three mental disorders. Our estimates are lower than those reported among paramedics in a recent national study of Public Safety Personnel in Canada [9]. This is encouraging because, while our findings are admittedly limited to a single site, it suggests that when participant selection is carefully controlled, the prevalence of mental disorder symptoms among paramedics may be lower than has been previously described in this population.

Nevertheless, our findings are concerning for two reasons. First, our study supports the position that the prevalence of mental disorder symptoms among paramedics is significantly higher than rates observed in the general population in Canada $[9,10,13,19,62]$. In total, 1 in 4 of the activeduty paramedics in our study site met the screening threshold for any one of the three mental disorders we screened for - a problem that has likely only worsened since the emergence of the 
COVID-19 pandemic. What we don't know is the degree to which this proportion of participants have sought or are undergoing care for these symptoms. A number of studies speak to the stigmatization of mental illness within the public safety professions [63-65], and the reluctance of Public Safety Personnel to seek out professional help $[2,65,66]$. It is unfortunately likely that many are not receiving care at all. Understanding barriers to accessing mental health care among paramedics is an important topic for future research.

Our second objective was to examine the associations between various demographic characteristics and the risk of screening positive for PTSD, major depressive disorder, or generalized anxiety disorder. Previous research in the Canadian population would suggest that women are more likely than men to report current or past-year prevalence of any of the three, and that age, socioeconomic status, and education are also important predictors of mental health [67]. Similarly, recent findings point to differences in the risk of mental disorder symptoms among paramedics when stratified by gender, age, education, and relationship status $[9,19,62]$. Our findings both align and contrast with this body of research. First, we did observe differences in risk attributable to gender. In our adjusted models, women were more likely to screen positive for major depressive disorder and generalized anxiety disorder, but less likely for PTSD. Helpseeking behavior has been shown to differ across genders [68]. This plays out particularly with depression, where, among men, hegemonic conceptualizations of masculinity and stigma conspire to limit reporting and diagnosis $[68,69]$. Among our sample, it may be that women are more willing to disclose symptoms and - for PTSD - more likely to be off work because of this gendered difference in help-seeking. In total, 61 members of the paramedic service were on leave due to 'disability' (using the language of the paramedic service) during the study, although we 
do not know the distribution of genders of the paramedics who were on leave. Further exploration of gendered differences in help-seeking and stigma in the context of public safety work is a topic worthy of further study.

Our findings also diverged from previous research among paramedics in the risk of mental disorder symptoms when stratified by relationship status, education, and provider classification. Whereas previous studies have found higher rates of mental disorders among advanced care paramedics [66] and protective effects of higher education [9,62] and being in a relationship [9,62], our findings did not bear this out. The only exception was where we found that participants with university level education were half as likely to screen positive for generalized anxiety disorder. Given that women in our sample were more likely to attend university than men and more likely to screen positive for major depressive disorder or generalized anxiety disorder, we tested an interaction term between gender and education. While our point estimates for the term generally favored a protective effect (except for PTSD), our confidence intervals suggest that the effect is compatible with either an increased or decreased risk of mental disorder symptoms. Where we did observe significant associations were in the relationships between self-reported resilience, employment classification, age, and experience as a member of the service's peer support team. Of the three, resilience and experience as a peer supporter warrant careful consideration.

Resilience is generally held to be the degree to which an individual can 'bounce back' from adversity [70]. The thought is that resiliency skills are teachable, and we have seen a growing trend of developing (and marketing) workplace resiliency training programs. When evaluated empirically, the effects of workplace resiliency training are modest $[35,42,70-73]$, with research 
suggesting only small improvements in mental disorder symptoms, stigma-reduction, or attitudes toward help-seeking. For example, a longitudinal study of Calgary police officers after completing the R2MR program did not indicate improvement in self-reported mental disorder symptoms or resilience at 6 or 12 months following the intervention [45]. As a whole, the topic of resiliency training is not without controversy. Though cultivating resilience may be desirable, the narrative risks shifting the locus of control onto the individual, potentially removing the responsibility of employers to mitigate the risks posed by chronic workplace stressors or exposure to potentially psychologically traumatic events. Controversy aside, our findings consistently and strongly point to a relationship between self-reported resilience and the risk of a positive mental disorder screen. The topic warrants further study.

Peer support as a concept has been the subject of discussion in the public safety professions for many years, owing, in part to, critical incident stress management programs [74]. More broadly, peer support was popularized by the consumer-survivor movement of the 1970s in which patients eschewed the (at the time) paternalistic medical models of psychiatric care in favor of seeking out the support of likeminded people with lived experience [75]. Among Public Safety Personnel, efficacy evidence of peer support teams is mixed [76-78], but the health of the peer supporters themselves has not (to our knowledge) been studied. In our sample, we observed that being or having been a member of the service's peer support team was associated with a 4-fold increase in the risk of screening positive for PTSD and a more than 3-fold increase in the risk of screening positive for major depressive disorder. Interpreting this relationship is difficult. In our site, peer supporters were recruited on the basis of having lived experience with adversity, including mental health challenges, potentially confounding the association. That said, 
recruitment for the program occurred two years before our study, and our self-report symptom measures probe for symptoms present within the last 14-30 days. Although it is certainly possible that members of the peer support team screened positive for mental disorders at higher rates due to persistent symptoms from pre-existing mental health conditions, it is also possible that the vicarious exposure to potentially psychologically traumatic events in providing empathetic support to their colleagues places peer supporters at an increased risk of poor mental health, including mental disorders. Given the growing popularity of these programs and the dearth of both efficacy [77] and safety evidence, our findings emphasize the importance of studying peer support programs more closely, including the potential health consequences for peer supporters.

\section{Limitations}

Our findings should be interpreted within the context of certain limitations. First, cross-sectional research does not lend itself to establishing causality. We acknowledge that we are assuming that the mental disorder symptoms we studied are attributable in some way to the participants' work as paramedics. This is increasingly supported by policy, however, given the growth in legislation in which a diagnosis of PTSD among Public Safety Personnel is presumed to be work related to help facilitate access to treatment. Second, we acknowledge that self-report symptom measures, while widely used, are a surrogate outcome and not diagnostic in and of themselves. Third, while our study site was carefully selected to be illustrative of a large, sophisticated, urban paramedic service, it is nevertheless a single site, and readers must exercise caution in generalizing our findings. Fourth, our approach to modelling and subsequent statistical power depended on the event rate observed in our study. We could estimate this beforehand, but the basis for our study 
was predicated on an assumption of overestimated prevalence, the degree of which was difficult to know at the outset. We attempted to account for this in the design of our survey to limit the number of predictors, but we acknowledge a risk of overfitting our models. We would evaluate this risk as low, given that we had between seven and nine events per covariate [79]. Finally, our study excluded 107 members of the service who were on leave during recruitment, making our sample vulnerable to a degree of selection bias, but even so, we would suggest that our findings have unique value in reflecting the mental health of the active-duty workforce.

\section{Conclusion}

Our findings are encouraging in that the rates of symptom clusters consistent with various mental disorders that we observed in our study are lower than have been previously reported among paramedics in Canada. Although admittedly limited to a single site, this suggests that the ways in which we gather this data may have important implications for its interpretation. At the same time, the rates of mental disorder symptoms we observed are higher than reported in the Canadian population at large. Fully 1 in 4 active-duty paramedics in our study met the screening criteria symptom clusters consistent with either PTSD, major depressive disorder, or generalized anxiety disorder, pointing to a mental health crisis within the profession that - with the emergence of the COVID-19 pandemic - has likely only worsened. We echo the growing calls within scholarship and policy for urgent action to support the mental health and well-being of Public Safety Personnel in Canada.

\section{Funding}


This research was funded by a Canadian Institutes of Health Research (CIHR) catalyst grant (competition number 201809PPS). The article processing charge was covered by this grant.

\section{Acknowledgements}

We wish to express our gratitude and appreciation to Peel Regional Paramedic Services leadership team and the Ontario Public Services Employees Union (OPSEU) Local 277 for their support of this study, and to the members of the paramedic service for the important work they do in keeping our communities safe.

\section{Author Contributions}

Conceptualization, JM \& MM; Methodology, JM, ED, \& MM; Formal Analysis, JM \& ED; Investigation, JM, ED, \& SH; Writing - Original Draft Preparation, JM; Writing - Review \& Editing, ED, SH, SM, \& MM, Supervision - ED, SH, \& MM; Project Administration, MM; Funding Acquisition, JM \& MM.

\section{Institutional Review Board Statement}

The study was conducted according to the guidelines of the Declaration of Helsinki, and approved by the Hamilton Integrated Research Ethics Board (HiREB Project Number 7595), approved August 16, 2019.

\section{Informed Consent Statement}

Informed consent was obtained from all subjects involved in this study. 


\section{Data Availability Statement}

The data presented in this study are available on request from the corresponding author. The data are not publicly available due to privacy restrictions and data security procedures stipulated in the Research Ethics Board (REB) review of this project.

\section{Conflicts of Interest}

The authors report no conflicts of interest to declare. The Canadian Institutes of Health Research (CIHR) had no role in the design, execution, interpretation, or writing of the study. 
Running Head: MENTAL DISORDER SYMPTOMS AMONG PARAMEDICS

\section{References}

1. Berger, W.; Coutinho, E.S.; Figueira, I.; Marques-Portella, C.; Luz, M.P.; Neylan, T.C.; Marmar, C.R.; Mendlowicz, M.V. Rescuers at risk: a systematic review and metaregression analysis of the worldwide current prevalence and correlates of PTSD in rescue workers. Soc Psychiatry Psychiatr Epidemiol 2012, 47, 1001-1011, doi:10.1007/s00127011-0408-2.

2. Renkiewicz, G.K.; Hubble, M.W. Secondary Traumatic Stress in Emergency Services Systems (STRESS) Project: Quantifying and Predicting Compassion Fatigue in Emergency Medical Services Personnel. Prehospital emergency care : official journal of the National Association of EMS Physicians and the National Association of State EMS Directors 2021, 1-12, doi:10.1080/10903127.2021.1943578.

3. Bentley, M.A.; Crawford, J.M.; Wilkins, J.R.; Fernandez, A.R.; Studnek, J.R. An assessment of depression, anxiety, and stress among nationally certified EMS professionals. Prehospital emergency care : official journal of the National Association of EMS Physicians and the National Association of State EMS Directors 2013, 17, 330338, doi:10.3109/10903127.2012.761307.

4. Renkiewicz, G.K.; Hubble, M.W. Secondary traumatic stress in emergency services systems (STRESS) project: Quantifying personal trauma profiles for secondary stress syndromes in emergency medical services personnel with prior military service. Journal of Special Operations Medicine 2021, 21, 55-64.

5. Brooks, D.; Brooks, R. A systematic review: what factors predict Post-Traumatic Stress Symptoms in ambulance personnel? British Paramedic Journal 2021, 5, 18-24, doi:10.29045/14784726.2021.3.5.4.18.

6. Reardon, M.; Abrahams, R.; Thyer, L.; Simpson, P. Review article: Prevalence of burnout in paramedics: A systematic review of prevalence studies. Emergency medicine Australasia : EMA 2020, 32, 182-189, doi:10.1111/1742-6723.13478.

7. Vigil, N.H.; Grant, A.R.; Perez, O.; Blust, R.N.; Chikani, V.; Vadeboncoeur, T.F.; Spaite, D.W.; Bobrow, B.J. Death by Suicide-The EMS Profession Compared to the General Public. Prehospital emergency care : official journal of the National Association of EMS Physicians and the National Association of State EMS Directors 2019, 23, 340-345, doi:10.1080/10903127.2018.1514090.

8. Luftman, K.; Aydelotte, J.; Rix, K.; Ali, S.; Houck, K.; Coopwood, T.B.; Teixeira, P.; Eastman, A.; Eastridge, B.; Brown, C.V.; et al. PTSD in those who care for the injured. Injury 2017, 48, 293-296, doi:10.1016/j.injury.2016.11.001.

9. Carleton, R.N.; Afifi, T.O.; Turner, S.; Taillieu, T.; Duranceau, S.; LeBouthillier, D.M.; Sareen, J.; Ricciardelli, R.; MacPhee, R.; Groll, D.; et al. Mental disorder symptoms among public safety personnel in Canada. Can J Psychiatry 2018, 63, 54-64, doi:10.1177/0706743717723825.

10. Carleton, R.N.; Afifi, T.O.; Taillieu, T.; Turner, S.; Krakauer, R.; Anderson, G.S.; MacPhee, R.S.; Ricciardelli, R.; Cramm, H.A.; Groll, D.; et al. Exposures to potentially traumatic events among public safety personnel in Canada. Canadian Journal of Behavioural Science / Revue canadienne des sciences du comportement 2019, 51, 37-52, doi:10.1037/cbs0000115. 
11. Sommer, J.L.; El-Gabalawy, R.; Taillieu, T.; Afifi, T.O.; Carleton, R.N. Associations between Trauma Exposure and Physical Conditions among Public Safety Personnel: Associations entre l'exposition a un traumatisme et les problemes physiques chez le personnel de la sante publique. Can J Psychiatry 2020, 65, 548-558, doi:10.1177/0706743720919278.

12. Ricciardelli, R.; Czarnuch, S.; Afifi, T.O.; Taillieu, T.; Carleton, R.N. Public Safety Personnel's interpretations of potentially traumatic events. Occup Med (Lond) 2020, 70, 155-161, doi:10.1093/occmed/kqaa007.

13. Carleton, R.N.; Afifi, T.O.; Taillieu, T.; Turner, S.; Mason, J.E.; Ricciardelli, R.; McCreary, D.R.; Vaughan, A.D.; Anderson, G.S.; Krakauer, R.L.; et al. Assessing the Relative Impact of Diverse Stressors among Public Safety Personnel. Int J Environ Res Public Health 2020, 17, doi:10.3390/ijerph17041234.

14. Ricciardelli, R.; Carleton, R.N.; Groll, D.; Cramm, H. Qualitatively Unpacking Canadian Public Safety Personnel Experiences of Trauma and Their Well-Being. Canadian Journal of Criminology and Criminal Justice 2018, 1-12, doi:10.3138/cjccj.2017-0053.r2.

15. Regehr, C.; Hill, J.; Goldberg, G.; Hughes, J. Postmortem Inquiries and Trauma Responses in Paramedics and Firefighters. Journal of Interpersonal Violence 2016, 18, 607-622, doi:10.1177/0886260503251131.

16. Harenberg, S.; McCarron, M.C.; Carleton, R.N.; O’Malley, T.; Ross, T. Experiences of trauma, depression, anxiety, and stress in Western-Canadian HEMS personnnel. Journal of Community Safety \& Well-being 2018, 3, 18-21.

17. Carleton, R.N.; Afifi, T.O.; Turner, S.; Taillieu, T.; El-Gabalawy, R.; Sareen, J.; Asmundson, G.J.G. Chronic pain among public safety personnel in Canada. Canadian Journal of Pain 2017, 1, 237-246, doi:10.1080/24740527.2017.1410431.

18. Angehrn, A.; Teale Sapach, M.J.N.; Ricciardelli, R.; MacPhee, R.S.; Anderson, G.S.; Carleton, R.N. Sleep Quality and Mental Disorder Symptoms among Canadian Public Safety Personnel. Int J Environ Res Public Health 2020, 17, doi:10.3390/ijerph17082708.

19. Carleton, R.N.; Afifi, T.O.; Turner, S.; Taillieu, T.; LeBouthillier, D.M.; Duranceau, S.; Sareen, J.; Ricciardelli, R.; MacPhee, R.S.; Groll, D.; et al. Suicidal ideation, plans, and attempts among public safety personnel in Canada. Canadian Psychology/Psychologie canadienne 2018, 59, 220-231, doi:10.1037/cap0000136.

20. Turner, S.; Taillieu, T.; Carleton, R.N.; Sareen, J.; Afifi, T.O. Association between a history of child abuse and suicidal ideation, plans and attempts among Canadian public safety personnel: a cross-sectional survey. CMAJ Open 2018, 6, E463-E470, doi:10.9778/cmajo.20170153.

21. Regehr, C.; Goldberg, G.; Glancy, G.D.; Knott, T. Posttraumatic symptoms and disability in paramedics. Can J Psychiatry 2002, 47, 953-958.

22. Regehr, C. Bringing the Trauma Home: Spouses of Paramedics. Journal of Loss and Trauma 2005, 10, 97-114, doi:10.1080/15325020590908812.

23. Berger, W.; Figueira, I.; Maurat, A.M.; Bucassio, E.P.; Vieira, I.; Jardim, S.R.; Coutinho, E.S.; Mari, J.J.; Mendlowicz, M.V. Partial and full PTSD in Brazilian ambulance workers: prevalence and impact on health and on quality of life. J Trauma Stress 2007, 20, 637-642, doi:10.1002/jts.20242.

24. Studnek, J.R.; Crawford, J.M.; Wilkins, J.R., 3rd; Pennell, M.L. Back problems among emergency medical services professionals: the LEADS health and wellness follow-up study. Am J Ind Med 2010, 53, 12-22, doi:10.1002/ajim.20783. 
25. Rahimi, A.; Vazini, H.; Alhani, F.; Anoosheh, M. Relationship Between Low Back Pain With Quality of Life, Depression, Anxiety and Stress Among Emergency Medical Technicians. Trauma Mon 2015, 20, e18686, doi:10.5812/traumamon.18686.

26. Bracken-Scally, M.; McGilloway, S.; Gallagher, S.; Mitchell, J.T. Life after the emergency services: An exploratory study of well being and quality of life in emergency services retirees. Journal of Emergency Mental Health and Human Resilience 2014, 16, 44-51.

27. Sterud, T.; Hem, E.; Lau, B.; Ekeberg, Ø. Suicidal ideation and suicide attempts in a nationwide sample of operational Norwegian ambulance personnel $j$ Occup Health 2008, 50, 406-414.

28. Crowe, R.P.; Fernandez, A.R.; Pepe, P.E.; Cash, R.E.; Rivard, M.K.; Wronski, R.; Anderson, S.E.; Hogan, T.H.; Andridge, R.R.; Panchal, A.R.; et al. The association of job demands and resources with burnout among emergency medical services professionals. $J$ Am Coll Emerg Physicians Open 2020, 1, 6-16, doi:10.1002/emp2.12014.

29. Cash, R.E.; White-Mills, K.; Crowe, R.P.; Rivard, M.K.; Panchal, A.R. Workplace Incivility Among Nationally Certified EMS Professionals and Associations with Workforce-Reducing Factors and Organizational Culture. Prehospital emergency care : official journal of the National Association of EMS Physicians and the National Association of State EMS Directors 2019, 23, 346-355, doi:10.1080/10903127.2018.1502383.

30. Fullerton, L.; Oglesbee, S.; Weiss, S.J.; Ernst, A.A.; Mesic, V. Assessing the Prevalence and Predictors of Bullying Among Emergency Medical Service Providers. Prehospital emergency care : official journal of the National Association of EMS Physicians and the National Association of State EMS Directors 2019, 23, 9-14, doi:10.1080/10903127.2018.1470208.

31. Dopelt, K.; Wacht, O.; Strugo, R.; Miller, R.; Kushnir, T. Factors that affect Israeli paramedics' decision to quit the profession: a mixed methods study. Isr J Health Policy Res 2019, 8, 78, doi:10.1186/s13584-019-0346-0.

32. Donnelly, E.; Bradford, P.; Davis, M.; Hedges, C.; Socha, D.; Morassutti, P.; Pichika, S.C. What influences safety in paramedicine? Understanding the impact of stress and fatigue on safety outcomes Journal of the American College of Emergency Physicians 2020, 1, 460-473.

33. Koopmans, E.; Wagner, S.L.; Schmidt, G.; Harder, H. Emergency Response Services Suicide: A Crisis in Canada? Journal of Loss and Trauma 2017, 22, 527-539, doi:10.1080/15325024.2017.1360589.

34. Supporting Canada's public safety personnel: An action plan on post-traumatic stress injuries. 2019.

35. Joyce, S.; Shand, F.; Tighe, J.; Laurent, S.J.; Bryant, R.A.; Harvey, S.B. Road to resilience: a systematic review and meta-analysis of resilience training programmes and interventions. BMJ Open 2018, 8, e017858, doi:10.1136/bmjopen-2017-017858.

36. Clompus, S.R.; Albarran, J.W. Exploring the nature of resilience in paramedic practice: A psycho-social study. International emergency nursing 2016, 28, 1-7, doi:10.1016/j.ienj.2015.11.006.

37. Grant, L.; Kinman, G. Emotional Resilience in the Helping Professions and how it can be Enhanced. Health and Social Care Education 2014, 3, 23-34, doi:10.11120/hsce.2014.00040. 
38. Jackson, D.; Firtko, A.; Edenborough, M. Personal resilience as a strategy for surviving and thriving in the face of workplace adversity: a literature review. Journal of advanced nursing 2007, 60, 1-9, doi:10.1111/j.1365-2648.2007.04412.x.

39. Gayton, S.D.; Lovell, G.P. Resilience in ambulance service paramedics and its relationships with well-being and general health. Traumatology 2012, 18, 58-64, doi:10.1177/1534765610396727.

40. Stelnicki, A.M.; Jamshidi, L.; Fletcher, A.J.; Carleton, R.N. Evaluation of Before Operational Stress: A Program to Support Mental Health and Proactive Psychological Protection in Public Safety Personnel. Front Psychol 2021, 12, 511755, doi:10.3389/fpsyg.2021.511755.

41. Szeto, A.; Dobson, K.S.; Knaak, S. The Road to Mental Readiness for First Responders: A Meta-Analysis of Program Outcomes. Can J Psychiatry 2019, 64, 18S-29S, doi:10.1177/0706743719842562.

42. Dobson, K.S.; Szeto, A.; Knaak, S. The Working Mind: A Meta-Analysis of a Workplace Mental Health and Stigma Reduction Program. Can J Psychiatry 2019, 64, 39S-47S, doi:10.1177/0706743719842559.

43. van der Meulen, E.; van der Velden, P.G.; Setti, I.; van Veldhoven, M. Predictive value of psychological resilience for mental health disturbances: A three-wave prospective study among police officers. Psychiatry Res 2018, 260, 486-494, doi:10.1016/j.psychres.2017.12.014.

44. Joyce, S.; Shand, F.; Bryant, R.A.; Lal, T.J.; Harvey, S.B. Mindfulness-Based Resilience Training in the Workplace: Pilot Study of the Internet-Based Resilience@Work (RAW) Mindfulness Program. J Med Internet Res 2018, 20, e10326, doi:10.2196/10326.

45. Carleton, R.N.; Korol, S.; Mason, J.E.; Hozempa, K.; Anderson, G.S.; Jones, N.A.; Dobson, K.S.; Szeto, A.; Bailey, S. A longitudinal assessment of the road to mental readiness training among municipal police. Cogn Behav Ther 2018, 1-21, doi:10.1080/16506073.2018.1475504.

46. (CIPSRT), C.I.f.P.S.R.a.T. Glossary of terms: A shared understanding of the common terms used to describe psychological trauma (version 2.1). 2019.

47. Bigham, B.L.; Jensen, J.L.; Tavares, W.; Drennan, I.R.; Saleem, H.; Dainty, K.N.; Munro, G. Paramedic self-reported exposure to violence in the emergency medical services (EMS) workplace: a mixed-methods cross-sectional survey. Prehospital emergency care : official journal of the National Association of EMS Physicians and the National Association of State EMS Directors 2014, 18, 489-494, doi:10.3109/10903127.2014.912703.

48. Thoits, P.A. Mechanisms linking social ties and support to physical and mental health. $J$ Health Soc Behav 2011, 52, 145-161, doi:10.1177/0022146510395592.

49. Thoits, P.A. Stress and health: major findings and policy implications. J Health Soc Behav 2010, 51 Suppl, S41-53, doi:10.1177/0022146510383499.

50. Donnelly, E.A.; Chonody, J.; Campbell, D. Measuring Chronic Stress in the Emergency Medical Services. Journal of Workplace Behavioral Health 2014, 29, 333-353, doi:10.1080/15555240.2014.965824.

51. Donnelly, E. Work-related stress and posttraumatic stress in emergency medical services. Prehospital emergency care : official journal of the National Association of EMS Physicians and the National Association of State EMS Directors 2012, 16, 76-85, doi:10.3109/10903127.2011.621044. 
52. Rivard, M.K.; Cash, R.E.; Mercer, C.B.; Chrzan, K.; Panchal, A.R. Demography of the National Emergency Medical Services Workforce: A Description of Those Providing Patient Care in the Prehospital Setting. Prehospital emergency care : official journal of the National Association of EMS Physicians and the National Association of State EMS Directors 2021, 25, 213-220, doi:10.1080/10903127.2020.1737282.

53. Smith, B.W.; Dalen, J.; Wiggins, K.; Tooley, E.; Christopher, P.; Bernard, J. The brief resilience scale: assessing the ability to bounce back. Int J Behav Med 2008, 15, 194-200, doi:10.1080/10705500802222972.

54. Blevins, C.A.; Weathers, F.W.; Davis, M.; Witte, T.K.; Domino, J.L. The posttraumatic stress disorder checklist for DSM-5 (PCL-5): Development and initial psychometric evaluation. Journal of Traumatic Stress 2015, 28, 489-498, doi:10.1002/jts.

55. Wortmann, J.H.; Jordan, A.H.; Weathers, F.W.; Resick, P.A.; Dondanville, K.A.; HallClark, B.; Foa, E.B.; Young-McCaughan, S.; Yarvis, J.S.; Hembree, E.A.; et al. Psychometric analysis of the PTSD Checklist-5 (PCL-5) among treatment-seeking military service members. Psychol Assess 2016, 28, 1392-1403, doi:10.1037/pas0000260.

56. Kroenke, K.; Spitzer, R.L.; Williams, J. The PHQ-9: Validity of a brief depression severity measure. J Gen Intern Med 2001, 16, 606-613.

57. Kroenke, K.; Spitzer, R.L.; Williams, J.B.; Lowe, B. The Patient Health Questionnaire Somatic, Anxiety, and Depressive Symptom Scales: a systematic review. Gen Hosp Psychiatry 2010, 32, 345-359, doi:10.1016/j.genhosppsych.2010.03.006.

58. Spitzer, R.L.; Kroenke, K.; Williams, J.B.; Löwe, B. A brief measure for assessing generalized anxiety disorder. Arch Intern Med 2006, 1666, 1092-1097.

59. Mat Salleh, M.N.; Ismail, H.; Mohd Yusoff, H. Reliability and validity of a posttraumatic checklist-5 (PCL-5) among fire and rescue officers in Selangor, Malaysia. Journal of Health Research 2020, ahead-of-print, doi:10.1108/jhr-11-2019-0243.

60. Beard, C.; Hsu, K.J.; Rifkin, L.S.; Busch, A.B.; Bjorgvinsson, T. Validation of the PHQ9 in a psychiatric sample. J Affect Disord 2016, 193, 267-273, doi:10.1016/j.jad.2015.12.075.

61. Beard, C.; Bjorgvinsson, T. Beyond generalized anxiety disorder: psychometric properties of the GAD-7 in a heterogeneous psychiatric sample. J Anxiety Disord 2014, 28, 547-552, doi:10.1016/j.janxdis.2014.06.002.

62. Carleton, R.N.; Afifi, T.O.; Taillieu, T.; Turner, S.; El-Gabalawy, R.; Sareen, J.; Asmundson, G.J.G. Anxiety-related psychopathology and chronic pain comorbidity among public safety personnel. J Anxiety Disord 2018, 55, 48-55, doi:10.1016/j.janxdis.2018.03.006.

63. Ricciardelli, R.; Andres, E.; Kaur, N.; Czarnuch, S.; Carleton, R.N. Fit for public safety: Informing attitudes and practices tied to the hiring of public safety personnel. Journal of Workplace Behavioral Health 2019, 35, 14-36, doi:10.1080/15555240.2019.1664306.

64. Ricciardelli, R.; Carleton, R.N.; Mooney, T.; Cramm, H. "Playing the system": Structural factors potentiating mental health stigma, challenging awareness, and creating barriers to care for Canadian public safety personnel. Health 2020, 24, 259-278.

65. Carleton, R.N.; Afifi, T.O.; Turner, S.; Taillieu, T.; Vaughan, A.D.; Anderson, G.S.; Ricciardelli, R.; MacPhee, R.S.; Cramm, H.A.; Czarnuch, S.; et al. Mental health training, attitudes toward support, and screening positive for mental disorders. Cogn Behav Ther 2019, 1-19, doi:10.1080/16506073.2019.1575900. 
66. Donnelly, E.A.; Bradford, P.; Davis, M.; Hedges, C.; Klingel, M. Predictors of posttraumatic stress and preferred sources of social support among Canadian paramedics. Cjem 2016, 18, 205-212, doi:10.1017/cem.2015.92.

67. Canada, M.H.C.o. Overview of mental health data in Canada: Background, needs, and gaps. 2014.

68. Affleck, W.; Carmichael, V.; Whitley, R. Men's Mental Health: Social Determinants and Implications for Services. Can J Psychiatry 2018, 63, 581-589, doi:10.1177/0706743718762388.

69. Whitley, R. Men's Mental Health: Beyond Victim-Blaming. Can J Psychiatry 2018, 63, 577-580, doi:10.1177/0706743718758041.

70. Hartmann, S.; Weiss, M.; Newman, A.; Hoegl, M. Resilience in the Workplace: A Multilevel Review and Synthesis. Applied Psychology 2019, 69, 913-959, doi:10.1111/apps.12191.

71. Leppin, A.L.; Bora, P.R.; Tilburt, J.C.; Gionfriddo, M.R.; Zeballos-Palacios, C.; Dulohery, M.M.; Sood, A.; Erwin, P.J.; Brito, J.P.; Boehmer, K.R.; et al. The efficacy of resiliency training programs: a systematic review and meta-analysis of randomized trials. PLoS One 2014, 9, e111420, doi:10.1371/journal.pone.0111420.

72. Jones, N.; Whelan, C.; Harden, L.; Macfarlane, A.; Burdett, H.; Greenberg, N. Resilience-based intervention for UK military recruits: a randomised controlled trial. Occup Environ Med 2019, 76, 90-96, doi:10.1136/oemed-2018-105503.

73. Robertson, I.T.; Cooper, C.L.; Sarkar, M.; Curran, T. Resilience training in the workplace from 2003 to 2014: A systematic review. Journal of Occupational and Organizational Psychology 2015, 88, 533-562, doi:10.1111/joop.12120.

74. Everly, G.S.; Flannery, R.B.; Mitchell, J.T. Critical incident stress management (CISM): A review of the literature. Aggression and Violent Behavior 2000, 5, 23-40.

75. Cyr, C.; McKee, H.; O’Hagan, M.; Robyn, P. Making the case for peer support: Report to the peer support project committee of the mental health comission of Canada. 2010.

76. Feuer, B.S. First Responder Peer Support: An Evidence-Informed Approach. Journal of Police and Criminal Psychology 2021, doi:10.1007/s11896-020-09420-z.

77. Anderson, G.S.; Di Nota, P.M.; Groll, D.; Carleton, R.N. Peer Support and CrisisFocused Psychological Interventions Designed to Mitigate Post-Traumatic Stress Injuries among Public Safety and Frontline Healthcare Personnel: A Systematic Review. Int J Environ Res Public Health 2020, 17, doi:10.3390/ijerph17207645.

78. Gillard, S. Peer support in mental health services: where is the research taking us, and do we want to go there? J Ment Health 2019, 28, 341-344, doi:10.1080/09638237.2019.1608935.

79. Vittinghoff, E.; McCulloch, C.E. Relaxing the rule of ten events per variable in logistic and Cox regression. Am J Epidemiol 2007, 165, 710-718, doi:10.1093/aje/kwk052. 
